\title{
Unwarranted imaging for distant metastases in patients with newly diagnosed ductal carcinoma in situ and stage I and II breast cancer
}

\author{
Sasha Lupichuk, MD, MSc \\ Derek Tilley, MSc \\ Brae Surgeoner, MSc \\ Karen King, MD \\ Anil Abraham Joy, MD
}

Presented at the Canadian Association of Medical Oncologists Annual Scientific Meeting, Apr. 26, 2018, Toronto, Ont.

Accepted July 24, 2019

\section{Correspondence to:}

S. Lupichuk

Tom Baker Cancer Centre

Department of Oncology

1331 29th St NW

Calgary AB T2N 4N2

sasha.lupichuk@ahs.ca

DOI: 10.1503/cjs.003519
Background: In 2012, the American Society of Clinical Oncology (ASCO) released a Choosing Wisely Top Five list that included a recommendation against ordering advanced imaging tests to screen for metastases among asymptomatic patients with early breast cancer. Our provincial breast cancer staging guideline was subsequently updated. We report on the use of unwarranted bone scanning (BS), computed tomography (CT), nonbreast magnetic resonance imaging (MRI) and positron emission tomography (PET) among women diagnosed with stage 0-II breast cancer in Alberta in 2011-2015.

Methods: The cohort was retrospectively ascertained from the Alberta Cancer Registry. We used additional provincial data sources to obtain information about diagnostic imaging tests completed from biopsy to surgical date plus 4 months. The reason for each BS, CT, MRI and PET was abstracted. We calculated the frequency of advanced imaging tests completed for routine metastatic screening.

Results: Of 10142 patients included, 2887 (28.5\%) had at least 1 advanced imaging test completed for routine metastatic screening. Of these 2887 patients, $438(15.2 \%)$ had a follow-up BS, CT, MRI or PET, and 28 patients (1.0\%) had a nonbreast imageguided biopsy. Use of routine advanced imaging tests did not change clearly over time.

Conclusion: Our results demonstrate persistent use of advanced imaging tests for routine metastatic screening among patients with stage $0-$ II breast cancer despite the release of the ASCO Choosing Wisely recommendations and the update of our provincial breast cancer staging guideline. Investigation of strategies for guideline translation to improve upon value-based care of patients with early breast cancer is warranted.

Contexte : En 2012, l'American Society of Clinical Oncology (ASCO) a publié sa liste de 5 interventions à « Choisir avec soin », dans laquelle elle recommandait notamment de ne pas recourir aux techniques d'imagerie de pointe pour le dépistage des métastases chez les patientes atteintes d'un cancer du sein peu avancé et asymptomatique. Nos lignes directrices provinciales pour la stadification du cancer du sein ont été mises à jour en conséquence. Nous faisons aujourd'hui état de l'utilisation injustifiée de la scintigraphie osseuse (SO), de la tomodensitométrie (TDM), de l'imagerie par résonnance magnétique (IRM) non mammaire et de la tomographie par émission de positrons (TEP) chez les femmes ayant reçu un diagnostic de cancer du sein peu avancé (stade 0-II) en Alberta entre 2011 et 2015.

Méthodes : La cohorte a été réunie de manière rétrospective à partir du registre albertain du cancer. Nous avons utilisé d'autres sources de données provinciales pour obtenir des renseignements sur les épreuves d'imagerie diagnostique effectuées entre les dates de la biopsie et les dates de la chirurgie plus 4 mois. Le motif invoqué pour recourir à chaque SO, TDM, IRM et TEP a été recueilli. Nous avons calculé la fréquence des épreuves d'imagerie de pointe effectuées pour un dépistage de routine des métastases.

Résultats : Sur les 10142 patientes incluses, 2887 (28,5\%) avaient subi au moins 1 épreuve d'imagerie de pointe pour le dépistage de routine des métastases. Parmi ces 2887 patientes, $438(15,2 \%)$ ont subi une SO, une TDM, une IRM ou une TEP de suivi et 28 patientes $(1,0 \%)$ ont subi une biopsie non mammaire guidée par l'imagerie. L'utilisation de routine des épreuves d'imagerie de pointe n'a pas nettement changé avec le temps.

Conclusion : Selon nos résultats, l'utilisation des épreuves d'imagerie de pointe pour le dépistage de routine des métastases persiste chez les patientes atteintes d'un cancer du sein de stade $0-$ II, malgré la publication des recommandations Choisir avec soin de l'ASCO et la mise à jour de nos lignes directrices provinciales concernant la stadification du cancer du sein. Il faudra se pencher sur des stratégies pour améliorer l'adoption de lignes directrices relatives aux soins véritablement utiles pour les patientes atteintes d'un cancer du sein peu avancé. 
B reast cancer is the most commonly diagnosed cancer among adult women in Canada, and the absolute number of new cases identified each year is increasing as a result of our growing and aging population. ${ }^{1}$ Fortunately, owing to the implementation of organized screening programs, most women will be diagnosed with early-stage disease (ductal carcinoma in situ [DCIS], stage I or stage II breast cancer) $)^{1,2}$ and will be treated successfully with primary surgery plus adjuvant radiation and/or systemic therapies where applicable. In Alberta, the 5-year relative survival for ductal carcinoma in situ and stage I breast cancer is $100 \%$, and for stage II breast cancer it is $95 \%$. $^{3}$

As breast cancer is an important public health concern, opportunities to promote value-based care should be prioritized. ${ }^{4,5}$ Clinical practice guidelines recommend against routine screening for metastases with diagnostic imaging tests among patients with early breast cancer who do not have suggestive symptoms, signs or biochemical abnormalities. ${ }^{6-10}$ The likelihood of having radiologically evident distant disease is low, ${ }^{11-13}$ and hence use of routine staging tests would rarely change the therapeutic plan or alter outcomes. Furthermore, routine screening for metastases can increase patient anxiety, lead to further unnecessary tests and biopsies, delay definitive treatment and escalate health care costs. ${ }^{14-16}$ Despite published guidelines, imaging for metastases in early breast cancer has been common. ${ }^{17-22}$ The issue of unnecessary imaging for metastases in early breast cancer was highlighted by the American Society of Clinical Oncology (ASCO) in their inaugural Top Five list, which was released on Apr. 4, 2012, in response to the American Board of Internal Medicine's Choosing Wisely campaign. ${ }^{23}$ Subsequently, the Alberta Health Services clinical practice guideline on breast cancer staging was updated. ${ }^{8}$ The recommendation for routine bone scanning in the setting of stage II disease was removed and the Alberta Provincial Tumour Team on behalf of Alberta Health Services endorsed the prior recommendation that routine abdominal imaging for DCIS and stage I and II breast cancer was not required. We therefore hypothesized that the utilization of routine staging tests in the setting of early breast cancer would decrease over time. The aim of this study was to report on the use of advanced imaging tests among women diagnosed with DCIS and stage I and stage II breast cancer between Jan. 1, 2011, and Dec. 31, 2015, in Alberta. Although the ASCO Choosing Wisely recommendation specifically addressed bone scanning (BS), computed tomography (CT) and positron emission tomography (PET), we also included nonbreast magnetic resonance imaging (MRI) for the sake of completeness.

\section{Methods}

This retrospective, population-based cohort study was approved by the Health Research Ethics Board of Alberta Cancer Committee.

\section{Study population}

The Surveillance and Reporting department of CancerControl Alberta is able to collect and link data from the Alberta Cancer Registry, the CancerControl electronic medical record (EMR), the Canadian Institute for Health Information (CIHI) National Ambulatory Care Reporting System and Discharge Abstract Database, and physician billings to Alberta Health. We queried the Surveillance and Reporting department of CancerControl Alberta to identify all patients with DCIS and stage I and stage II breast cancer diagnosed between Jan. 1, 2011, and Dec. 31, 2015. Pathologic stage was recorded by the Alberta Cancer Registry on the basis of the American Joint Committee on Cancer staging manual, seventh edition. ${ }^{24}$ Any patients who did not undergo definitive breast cancer surgery (mastectomy or breast conservation plus sentinel node biopsy and/or axillary node dissection) were excluded. Furthermore, we excluded patients with stage III disease (where routine screening for metastases is warranted) and patients with de novo stage IV disease (whose metastatic classification may or may not have been based on routine imaging tests). For each eligible patient, we collected the following information: age at diagnosis, setting of diagnosis (urban or nonurban, and provincial health zone), date of first breast biopsy that confirmed DCIS or invasive breast cancer, date of first breast surgery after biopsy, definitive breast surgery type (breast conservation or mastectomy) and stage (DCIS, stage I or stage II). For the patients with stage I and II breast cancer, we additionally recorded nodal status (positive or negative), tumour grade (1, 2 or 3), presence of lymphovascular invasion (yes or no), hormone receptor (HR) status (positive or negative), human epidermal growth factor receptor 2 (HER2) status (positive or negative) and use of adjuvant radiation and/or chemotherapy.

\section{Imaging quantification and classification}

Imaging data were obtained through both the Alberta Health Services Data Repository for Reporting (AHSDRR) diagnostic imaging database and physician billings to Alberta Health. The staging window was defined as the date of first breast biopsy confirming DCIS or invasive cancer to the first surgical date plus 4 months. We recorded the following types of diagnostic imaging tests performed during the staging window: plain chest radiograph, BS, CT, breast and nonbreast MRI, PET and nonbreast image-guided biopsy. For each imaging test, the following information was collected: anatomic region, date of test, location of test, ordering physician's specialty if available and indication for imaging as recorded on the requisition if available.

For patients with DCIS or stage I or II breast cancer who had a BS, CT, MRI or PET scan completed during 
the staging window, we reviewed the EMR to obtain test indication where not obvious from the AHSDRR Diagnostic Imaging database. For BS, CT, MRI and PET, test indication was categorized as follows: routine screening for distant metastases, screening for distant metastases on the basis of patient symptoms or signs, follow-up to a previously abnormal test, advanced breast imaging with MRI, CT or MRI angiography for planning of autologous breast reconstruction, or unrelated to breast cancer diagnosis.

\section{Analysis}

The cohort of eligible patients was described according to patient, demographic, breast cancer and treatment characteristics. Each eligible patient was classified as having undergone routine screening for distant metastases or not. Routine screening or staging was defined as having undergone at least $1 \mathrm{BS}, \mathrm{CT}, \mathrm{MRI}$ or PET scan in the absence of symptoms or signs concerning for metastatic disease. We did not consider the following to be routine staging tests: advanced breast imaging with MRI or CT/MRI angiography for planning of autologous reconstruction, and BS, CT, MRI or PET scanning completed for indications not related to or not obviously related to the breast cancer diagnosis. We calculated the frequency of routine staging tests by patient and number of tests. These outcomes were further evaluated by stage and type of imaging modality. As an additional end point, we calculated the frequency of preoperative chest radiography.

Patients with stage I and II breast cancer who underwent routine screening for metastases were compared with those who did not using monovariate $\left(\chi^{2}\right)$ and multivariate (logistic regression) analyses on the following variables: age group (<40, 40-49, 50-59, 60-69, $\geq 70$ yr), Charlson Comorbidity Index (CCI) score $(0,1, \geq 2)$, diagnosis setting (urban, nonurban), diagnosis year (2011, 2012, 2013, 2014, 2015), type of surgery (breast conservation, mastectomy), receipt of preoperative chest radiography (no, yes), stage (I, II), tumour grade $(1,2,3)$, lymphovascular invasion (no, yes), lymph node status (negative, positive), HER2 status (negative, positive) and triple-negative (estrogen receptor [ER], progesterone receptor [PR] and HER2 negative) status (no, yes). Further monovariate and multivariate sensitivity analyses were conducted. With the exclusion of patients who received neoadjuvant chemotherapy, we compared those who had routine screening with those who did not on the same variables. We also included the patients with DCIS and compared those who had routine screening with those who did not on applicable variables: age group, CCI, diagnosis setting, diagnosis year, type of surgery, receipt of preoperative chest radiography and stage.

Additionally, monovariate analysis $\left(\chi^{2}\right)$ was used to compare the frequency of patients undergoing routine screening for metastases (total and by type of imaging modality) by Choosing Wisely era. ASCO's Choosing Wisely recommendation against using advanced imaging tests for routine staging in early breast cancer was released Apr. 4, 2012. Granting time for dissemination of information, we defined the pre-Choosing Wisely era as diagnosis years 2011-2012 and the post-Choosing Wisely era as diagnosis years 2013-2015.

All statistical analyses were performed using SPSS Statistics version 19 (IBM).

\section{Results}

\section{Study population}

Table 1 describes patient, breast cancer and treatment characteristics for the entire study population and by status of having undergone at least 1 routine staging test or not. For the entire cohort, patients had a median age at diagnosis of 60 (range 21-98) years, were healthy (CCI score of 0 in $83.3 \%$ ) and most commonly received their diagnosis in an urban setting $(71.1 \%)$. In terms of stage distribution, $13.8 \%$ had DCIS, $46.4 \%$ had stage I breast cancer and $39.8 \%$ had stage II breast cancer. Most of the patients with stage I and II breast cancer had ER-positive (87.7\%) and HER2-negative $(87.4 \%)$ disease. The frequency of breast-conserving surgery $(55.8 \%)$ was similar to that for adjuvant radiation $(56.2 \%)$, while only $32.7 \%$ had chemotherapy (28\% adjuvant and $4.7 \%$ neoadjuvant). Patients who underwent at least 1 routine staging test tended to be younger, were more often diagnosed in a nonurban setting and had breast cancer characteristics as follows: higher stage, lymph node positive, higher grade, presence of lymphovascular invasion (LVI), HER2 positive and triple negative. Furthermore, screened patients had a higher frequency of also having undergone preoperative chest radiography and were more likely to be treated with mastectomy, radiation and chemotherapy.

\section{Use of advanced imaging tests for routine metastatic screening}

Figure 1 outlines how patients who underwent routine imaging tests to screen for metastatic disease were identified. In the study period, 10142 patients underwent breast surgery for management of DCIS or stage I or stage II breast cancer. For this cohort, 6321 advanced imaging tests (BS, CT, MRI or PET) were identified during the staging window among 3845 patients. Of these advanced imaging tests, 1437 were excluded for the following reasons: advanced breast imaging with MRI (173); CT/MRI angiography for planning of autologous reconstruction (50); BS, CT, MRI or PET scanning completed for an indication not related to the breast cancer diagnosis (1185); and CT scanning completed for reasons unknown (29). Furthermore, 651 tests were excluded as the patient 
Table 1 (part 1 of 2). Patient, breast cancer and treatment characteristics of study population

\begin{tabular}{|c|c|c|c|c|}
\hline \multirow[b]{2}{*}{ Characteristic } & \multicolumn{2}{|c|}{ No. $(\%)$ of patients; ${ }^{*}$ receipt of imaging test } & \multirow[b]{2}{*}{$p$ value } & \multirow{2}{*}{$\begin{array}{c}\text { No. (\%) of patients } \\
\text { Entire cohort } \\
n=10142\end{array}$} \\
\hline & $\begin{array}{l}\text { Routine } \mathrm{BS}, \mathrm{CT}, \mathrm{MRI} \text { or PET } \\
\quad n=2887\end{array}$ & $\begin{array}{c}\text { No routine } \mathrm{BS}, \mathrm{CT}, \mathrm{MRI} \text { or } \mathrm{PET} \\
n=7255\end{array}$ & & \\
\hline Age group, yr & & & $<0.001$ & \\
\hline$\leq 40$ & $234(8.1)$ & $273(3.8)$ & & $507(5.0)$ \\
\hline $41-50$ & $550(19.1)$ & 1107 (15.3) & & 1657 (16.3) \\
\hline $51-60$ & $773(26.8)$ & 1915 (26.4) & & $2688(26.5)$ \\
\hline $61-70$ & $737(25.5$ & $1982(27.3)$ & & 2719 (26.8) \\
\hline$>70$ & $593(20.5)$ & 1978 (27.3) & & $2571(25.4)$ \\
\hline $\mathrm{CCl}$ score & & & 0.476 & \\
\hline 0 & $2420(84.0)$ & 5971 (83.1) & & 8391 (83.3) \\
\hline 1 & $342(11.9)$ & $915(12.7)$ & & $1257(12.5)$ \\
\hline$\geq 2$ & $118(4.1)$ & $302(4.2)$ & & $420(4.2)$ \\
\hline Unknown, no. & 7 & 67 & & 74 \\
\hline Year of diagnosis & & & 0.008 & \\
\hline 2011 & 567 (19.6) & $1317(18.2)$ & & $1884(18.6)$ \\
\hline 2012 & $554(19.2)$ & 1370 (18.9) & & $1924(19.0)$ \\
\hline 2013 & $529(18.3)$ & $1452(20.0)$ & & 1981 (19.5) \\
\hline 2014 & $654(22.7)$ & 1497 (20.6) & & $2151(21.2)$ \\
\hline 2015 & $583(20.2)$ & 1619 (22.3) & & $2202(21.7)$ \\
\hline Zone at diagnosis ${ }^{\dagger}$ & & & $<0.001$ & \\
\hline $\mathrm{Z1}$ & $603(20.9)$ & 2740 (37.8) & & $3343(33.0)$ \\
\hline Z2 & $1192(41.3)$ & 2676 (36.9) & & 3868 (38.1) \\
\hline Z3 & $451(15.6)$ & $342(4.7)$ & & 793 (7.8) \\
\hline Z4 & $403(14.0)$ & $862(11.9)$ & & $1265(12.5)$ \\
\hline $\mathrm{Z5}$ & $238(8.2)$ & 635 (8.8) & & $873(8.6)$ \\
\hline Setting of diagnosis & & & $<0.001$ & \\
\hline Urban & $1795(62.2)$ & $5416(74.7)$ & & $7211(71.1)$ \\
\hline Rural & 1092 (37.8) & 1839 (25.3) & & 2931 (28.9) \\
\hline $\begin{array}{l}\text { Preoperative chest } \\
\text { radiograph }\end{array}$ & & & $<0.001$ & \\
\hline Yes & $988(34.2)$ & $1926(26.5)$ & & $2914(28.7)$ \\
\hline No & 1899 (65.8) & 5329 (73.5) & & 7228 (71.3) \\
\hline Surgery & & & $<0.001$ & \\
\hline Mastectomy & 1612 (55.9) & 2869 (39.6) & & $4481(44.2)$ \\
\hline BCS & $1274(44.1)$ & $4382(60.4)$ & & 5656 (55.8) \\
\hline Unknown, no. & 1 & 4 & & 5 \\
\hline Stage & & & $<0.001$ & \\
\hline 0 (DCIS) & $52(1.8)$ & 1345 (18.5) & & $1397(13.8)$ \\
\hline 1 & $759(26.3)$ & 3949 (54.4) & & $4708(46.4)$ \\
\hline$\|$ & 2076 (71.9) & $1961(27.0)$ & & 4037 (39.8) \\
\hline Lymph dode & & & $<0.001$ & \\
\hline Positive & 1310 (48.3) & $598(8.6)$ & & 1908 (19.8) \\
\hline Negative & $1401(51.7)$ & $6351(91.4)$ & & $7752(80.2)$ \\
\hline Unknown, no. & 176 & 306 & & 482 \\
\hline Grade & & & $<0.001$ & \\
\hline 1 & $347(12.2)$ & $1459(21.2)$ & & $1806(18.6)$ \\
\hline 2 & $1190(41.8)$ & $2921(42.5)$ & & $4111(42.3)$ \\
\hline 3 & $1307(46.0)$ & 2490 (36.2) & & 3797 (39.1) \\
\hline Unknown, no. & 43 & 385 & & 428 \\
\hline LVI & & & $<0.001$ & \\
\hline Present & 1002 (36.5) & 109615.4) & & 2098 (21.3) \\
\hline Absent & 1745 (63.5) & 6002 (84.6) & & 7747 (78.7) \\
\hline Unknown, no. & 140 & 157 & & 297 \\
\hline ER status & & & $<0.001$ & \\
\hline Positive & 2443 (85.3) & 5834 (88.8) & & 8277 (87.7) \\
\hline Negative & $422(14.7)$ & $736(11.2)$ & & $1158(12.3)$ \\
\hline Unknown, no. & 22 & 685 & & 707 \\
\hline
\end{tabular}


Table 1 (part 2 of 2). Patient, breast cancer and treatment characteristics of study population

\begin{tabular}{|c|c|c|c|c|}
\hline \multirow[b]{2}{*}{ Characteristic } & \multicolumn{2}{|c|}{ No. (\%) of patients; ${ }^{*}$ receipt of imaging test } & \multirow[b]{2}{*}{$p$ value } & \multirow{2}{*}{$\begin{array}{c}\text { No. }(\%) \text { of patients } \\
\text { Entire cohort } \\
n=10142\end{array}$} \\
\hline & $\begin{array}{c}\text { Routine } \mathrm{BS}, \mathrm{CT}, \mathrm{MRI} \text { or PET } \\
\qquad n=2887\end{array}$ & $\begin{array}{c}\text { No routine } \mathrm{BS}, \mathrm{CT}, \mathrm{MRI} \text { or PET } \\
\qquad n=7255\end{array}$ & & \\
\hline PR status & & & $<0.001$ & \\
\hline Positive & $2127(74.2)$ & 5113 (77.9) & & 7240 (76.8) \\
\hline Negative & $738(25.8)$ & $1449(22.1)$ & & $2187(23.2)$ \\
\hline Unknown, no. & 22 & 693 & & 715 \\
\hline HER2 status & & & $<0.001$ & \\
\hline Positive & 459 (16.5) & $621(10.7)$ & & 1080 (12.6) \\
\hline Negative & 2319 (83.5) & 5159 (89.3) & & 7478 (87.4) \\
\hline Unknown, no. & 109 & 1475 & & 1584 \\
\hline TNBC & & & 0.006 & \\
\hline Yes & $262(9.4)$ & $444(7.7)$ & & 706 (8.3) \\
\hline No & 2516 (90.6) & 5331 (92.3) & & 7847 (91.7) \\
\hline Unknown, no. & 109 & 1480 & & 1589 \\
\hline Chemotherapy & & & $<0.001$ & \\
\hline Yes & 1685 (58.4) & 1635 (22.5) & & $3320(32.7)$ \\
\hline No & 1202 (41.6) & $5620(77.5)$ & & $6822(67.3)$ \\
\hline Radiotherapy & & & $<0.001$ & \\
\hline Yes & $1723(59.7)$ & 3980 (54.9) & & $5703(56.2)$ \\
\hline No & $1164(40.3)$ & $3275(45.1)$ & & 4439 (43.8) \\
\hline \multicolumn{5}{|c|}{$\begin{array}{l}\mathrm{BCS}=\text { breast-conserving surgery; } \mathrm{BS}=\text { bone scanning; } \mathrm{CCl}=\text { Charlson Comorbidity Index; } \mathrm{CT}=\text { computed tomography; } \mathrm{DCIS}=\text { ductal carcinoma in situ; } \\
\mathrm{ER}=\text { estrogen receptor; } \mathrm{HER2}=\text { human epidermal growth factor receptor } 2 ; \mathrm{LVI}=\text { Iymphovascular invasion; } \mathrm{MRI}=\text { magnetic resonance imaging; } \mathrm{PET}= \\
\text { positron emission tomography; } \mathrm{PR}=\text { progesterone receptor; } \mathrm{TNBC}=\text { triple-negative breast cancer. }\end{array}$} \\
\hline
\end{tabular}

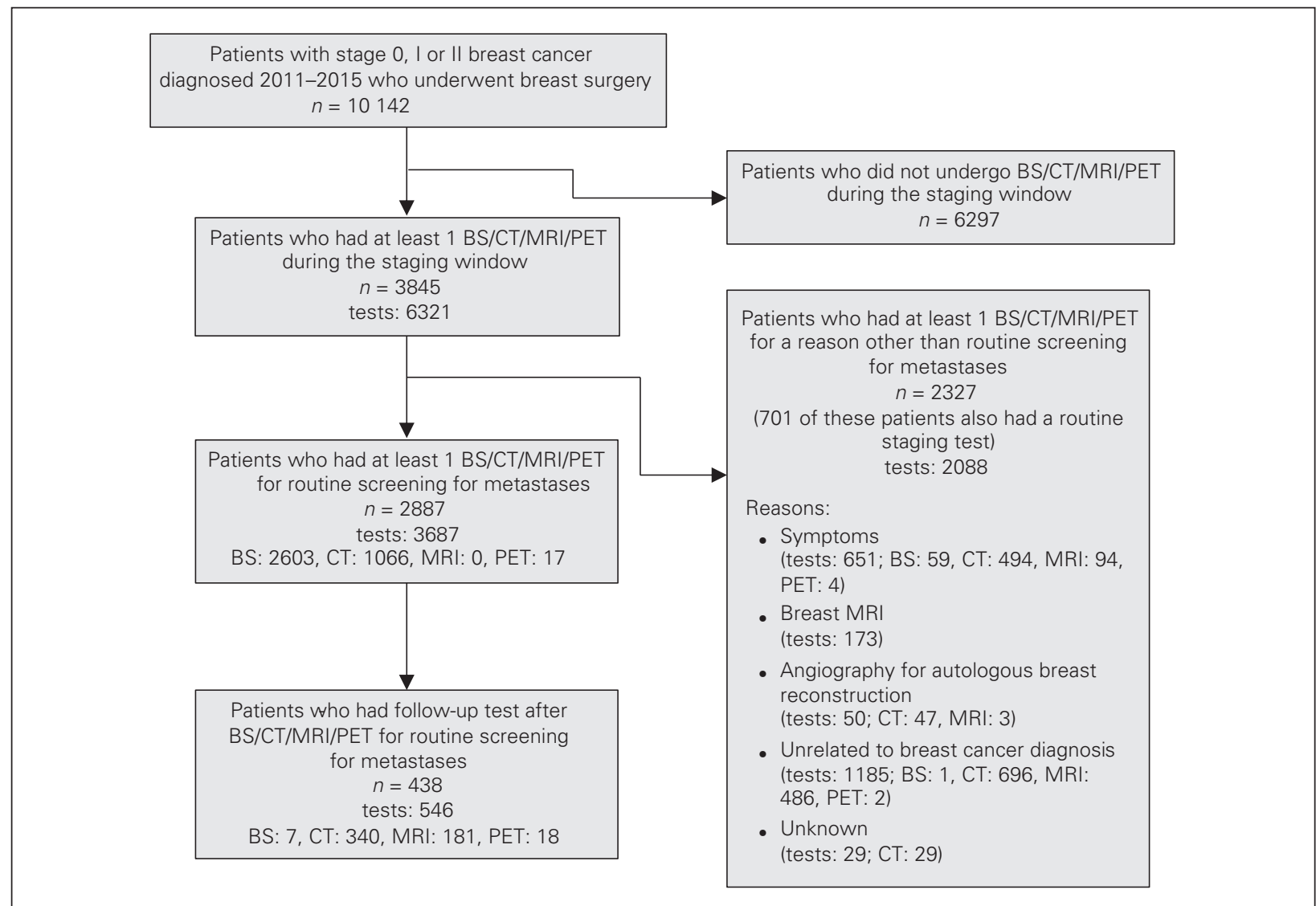

Fig. 1. Study flow chart. $B S=$ bone scan; $C T=$ computed tomography; $M R I=$ magnetic resonance imaging; $P E T=$ positron emission tomography. 
was reported to have symptoms or signs worrisome for distant disease. These 651 tests were among 541 patients, meaning that $5.2 \%$ of the patients in our study cohort underwent screening for metastatic disease for a potentially valid reason. Finally, 546 tests were excluded because of categorization as a follow-up test. This left 3687 tests having been completed for routine staging among 2887 patients. Hence, the incidence of patients who underwent routine screening for metastases was $28.5 \%$, and the mean number of tests per patient was 1.3 (standard deviation 0.5 ). The incidence of routine screening was $3.7 \%$ among patients with DCIS, $16.1 \%$ among those with stage I breast cancer and 51.4\% among those with stage II breast cancer (Table 2). Patients were most commonly subjected to BS, followed by CT and then PET; none of our patients had an MRI for routine screening (Table 2). Of the 2887 patients who underwent routine screening, 546 follow-up tests (most commonly CT and MRI) were completed during the staging window among 438 patients (15.2\%). Furthermore, we identified 28 patients who underwent a nonbreast image-guided biopsy (1.0\%).

\section{Monovariate and multivariate analyses}

For patients with stage I and II breast cancer, monovariate and multivariate analyses revealed significant associations between the following variables and routine staging: age ( $\geq 70 \mathrm{yr}$ relative to younger age groups), year of diagnosis (2011 relative to 2013 and 2015 but not relative to 2012 or 2014), setting of diagnosis (nonurban relative to urban), type of surgery (mastectomy relative to breast-conserving surgery), stage (II relative to I), lymph node status (positive relative to negative), grade ( 2 and 3 relative to 1 ) and HER2 status (positive relative to negative) (Table 3). Preoperative chest radiography (yes relative to no), LVI (positive relative to negative) and triple-negative status (yes v. no) were significantly associated with routine staging with monovariate analysis only, while CCI score was not associated with routine staging using monovariate or multivariate analysis (Table 3). Exclusion of patients who received neoadjuvant treatment did not change the results of the monovariate and multivariate analyses. With inclusion of patients with DCIS, significant associations with routine staging persisted for the applicable variables (age, year of diagnosis, setting of diagnosis, type of surgery and stage).

\section{Pre- versus post-Choosing Wisely eras}

In a further exploratory analysis, we investigated the influence of Choosing Wisely era on the use of routine staging with BS, CT and PET. Overall, total use of BS, CT and PET was unchanged between the pre- and post-Choosing Wisely eras (Fig. 2). For the separate routine imaging modalities considered, utilization of CT significantly increased ( $7.5 \%$ pre-Choosing Wisely era v. $10.8 \%$ postChoosing Wisely era, $p<0.001)$.

\section{Discussion}

To our knowledge, we have presented the first provincial, population-based study to report on the use of advanced imaging tests for routine investigation of metastases among women diagnosed with DCIS or stage I or stage II breast cancer during an era that spanned the release of ASCO's Choosing Wisely recommendations. Of 10142 patients who had received a diagnosis in the years 2011 through 2015, $2886(28.5 \%)$ had at least $1 \mathrm{BS}$, CT or PET completed for routine staging purposes between the date of first breast biopsy confirming DCIS or invasive cancer and the first surgical date plus 4 months. Bone scanning was the most frequently ordered modality followed by CT and then PET; MRI was not used for routine staging purposes. Of the 2886 patients who had an advanced imaging test for routine staging, $438(15.2 \%)$ had a follow-up BS, CT, MRI or PET, and $28(1.0 \%)$ had a nonbreast imageguided biopsy within the staging window.

Simos and colleagues reported on the use of plain radiography, ultrasonography, BS, CT and MRI for routine staging among patients with stage I or II breast cancer in the years 2007 through 2012 in Ontario. ${ }^{20}$ In their provincial cohort, $85.9 \%$ of patients underwent at least 1 of these tests. Considering the initial advanced imaging tests completed for patients with stage I or II breast cancer in the final year of the Ontario cohort, we can make some comparisons with our Alberta cohort (Fig. 2 in Simos and colleagues and Table 2 in our study). In both cohorts, BS was used more than CT. Their use of BS appeared higher

\begin{tabular}{|c|c|c|c|c|c|}
\hline \multirow[b]{2}{*}{ Stage } & \multicolumn{5}{|c|}{ No. (\%) of patients who underwent imaging; imaging modality } \\
\hline & BS & CT & MRI & PET & Total \\
\hline DCIS, $n=1397$ & $36(2.6)$ & $20(1.4)$ & $0(0)$ & $0(0)$ & $52(3.7)$ \\
\hline I, $n=4708$ & $661(14.0)$ & $207(4.4)$ & $0(0)$ & $6(0.1)$ & $759(16.1)$ \\
\hline$\|, n=4037$ & $1880(46.6)$ & 746 (18.5) & $0(0)$ & $12(0.3)$ & 1961 (51.4) \\
\hline
\end{tabular}


Table 3. Monovariate and multivariate analyses of use of routine bone scanning, computed tomography, magnetic resonance imaging and positron emission tomography in patients with stage I and II breast cancer

\begin{tabular}{|c|c|c|c|c|}
\hline \multirow[b]{2}{*}{ Variable } & \multicolumn{2}{|c|}{ Monovariate analysis } & \multicolumn{2}{|c|}{ Multivariate analysis } \\
\hline & OR $(95 \% \mathrm{Cl})$ & $p$ value & OR $(95 \% \mathrm{Cl})$ & $p$ value \\
\hline \multicolumn{5}{|l|}{ Age group, yr } \\
\hline$\geq 70$ & Ref & & Ref & \\
\hline $60-69$ & $1.240(1.095-1.405)$ & 0.001 & $1.206(1.029-1.412)$ & 0.020 \\
\hline $50-59$ & $1.346(1.189-1.524)$ & $<0.001$ & $1.267(1.081-1.485)$ & 0.004 \\
\hline $40-49$ & $1.657(1.445-1.901)$ & $<0.001$ & $1.379(1.154-1.648)$ & $<0.001$ \\
\hline$<40$ & $2.859(2.347-3.482)$ & $<0.001$ & $1.551(1.202-2.002)$ & 0.001 \\
\hline \multicolumn{5}{|l|}{$\mathrm{CCl}$ score } \\
\hline 0 & Ref & & Ref & \\
\hline 1 & $0.922(0.807-1.053)$ & 0.232 & $0.891(0.752-1.055)$ & 0.18 \\
\hline$\geq 2$ & 0.964 (0.775-1.199) & 0.742 & $0.807(0.609-1.070)$ & 0.14 \\
\hline \multicolumn{5}{|c|}{ Year of diagnosis } \\
\hline 2011 & Ref & & Ref & \\
\hline 2012 & $0.939(0.817-1.080)$ & 0.378 & $0.886(0.743-1.058)$ & 0.18 \\
\hline 2013 & $0.846(0.736-0.973)$ & 0.019 & $0.821(0.687-0.980)$ & 0.029 \\
\hline 2014 & $1.015(0.887-1.161)$ & 0.831 & $1.011(0.852-1.199)$ & 0.90 \\
\hline 2015 & $0.836(0.730-0.959)$ & 0.010 & $0.729(0.612-0.868)$ & $<0.001$ \\
\hline \multicolumn{5}{|c|}{ Setting of diagnosis } \\
\hline Urban & Ref & & Ref & \\
\hline Rural & $1.792(1.634-1.964)$ & $<0.001$ & $2.107(1.871-2.372)$ & $<0.001$ \\
\hline \multicolumn{5}{|l|}{ Surgery } \\
\hline Mastectomy & Ref & & Ref & \\
\hline BCS & $0.517(0.474-0.565)$ & $<0.001$ & $0.687(0.614-0.768)$ & $<0.001$ \\
\hline \multicolumn{5}{|l|}{ Stage } \\
\hline 0 (DCIS) & NA & & NA & \\
\hline 1 & Ref & & Ref & \\
\hline II & $5.508(4.988-6.083)$ & $<0.001$ & $2.254(1.963-2.588)$ & $<0.001$ \\
\hline \multicolumn{5}{|c|}{ Lymph node status } \\
\hline Negative & Ref & & Ref & \\
\hline Positive & 9.931 (8.872-11.115 & $<0.001$ & $4.763(4.094-5.541)$ & $<0.001$ \\
\hline \multicolumn{5}{|l|}{ Grade } \\
\hline 1 & Ref & & Ref & \\
\hline 2 & $1.713(1.496-1.961$ & $<0.001$ & $1.343(1.141-1.581)$ & $<0.001$ \\
\hline 3 & 2.207 (1.929-2.526 & $<0.001$ & 1.569 (1.308-1.883) & $<0.001$ \\
\hline \multicolumn{5}{|l|}{ LVI } \\
\hline Absent & Ref & & Ref & \\
\hline Present & 3.145 (2.843-3.478 & $<0.001$ & 1.035 (0.905-1.183) & 0.62 \\
\hline \multicolumn{5}{|l|}{ HER2 status } \\
\hline Negative & Ref & & Ref & \\
\hline Positive & $1.644(1.444-1.873$ & $<0.001$ & $1.248(1.051-1.483)$ & 0.012 \\
\hline \multicolumn{5}{|l|}{ TNBC } \\
\hline No & Ref & & Ref & \\
\hline Yes & $1.250(1.066-1.467$ & 0.006 & $1.110(0.903-1.364)$ & 0.32 \\
\hline
\end{tabular}

for patients with stage I breast cancer (around 30\% in 2012 in Ontario v. 14\% in all years in Alberta) and for patients with stage II breast cancer (around 55\% in 2012 in Ontario v. $46.6 \%$ in all years in Alberta). Their use of CT appeared only slightly higher for patients with stage I breast cancer (around 8\% in 2012 in Ontario v. 4.4\% in all years in Alberta) and for patients with stage II breast cancer (around $20 \%$ in 2012 in Ontario v. $18.5 \%$ in all years in Alberta). The finding that higher proportions of patients with stage I and II breast cancer underwent BS and CT in Ontario could be explained by potential inclusion of symptomatic patients and patients undergoing tests for other reasons (such patients were excluded from our study), differences in staging guidelines (the Ontario guideline included BS for patients with stage II breast cancer $^{6}$ but the Alberta guideline removed it for these 


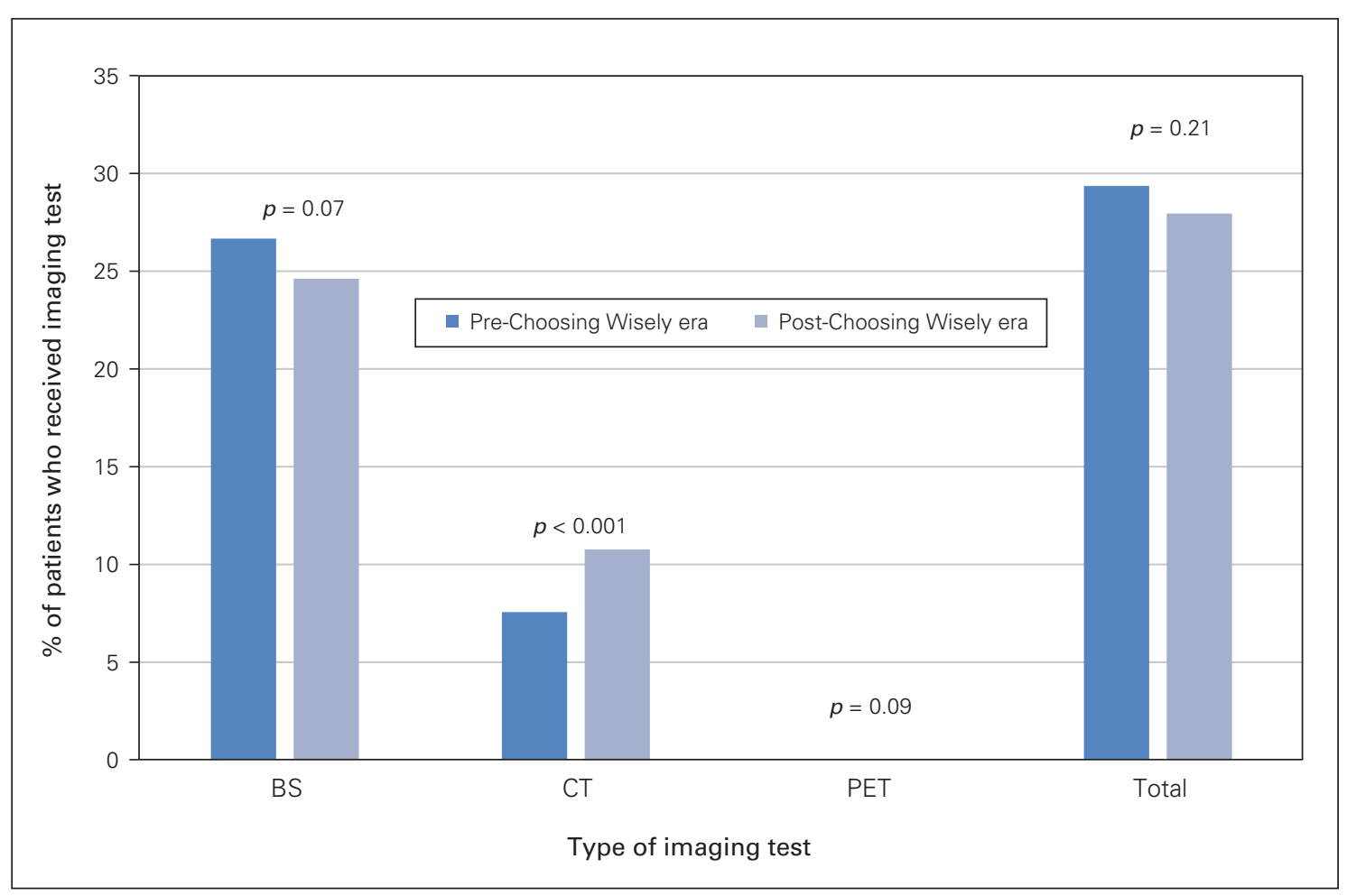

Fig. 2. Use of routine BS, CT and PET before and after the release of the American Society of Clinical Oncology's Choosing Wisely recommendations. BS = bone scan; CT = computed tomography; $\mathrm{PET}=$ positron emission tomography.

patients in $2012^{8}$ ), and the timing of the cohort in relation to the release of the ASCO Choosing Wisely recommendations. The timing of the cohort seems to be a less likely explanation as Simos and colleagues reported that although the proportion of women subjected to routine imaging for staging purposes remained relatively stable over time, the use of conventional tests (plain radiography, ultrasonography) decreased, and the use of some advanced tests (CT, MRI) increased. Our study also found a small but significant increase in the use of CT and overall no change in the use of advanced imaging tests before versus after the release of the ASCO Choosing Wisely recommendatoins.

The potential impact of ASCO's Choosing Wisely recommendations has been examined in other studies. A single institution in Ontario examined the records of 100 consecutive patients with breast cancer seen in 2011 and 100 consecutive patients with breast cancer seen in September to November 2012. ${ }^{25}$ The proportion of patients undergoing at least 1 staging test not concordant with the ASCO recommendations was $77 \%$ in 2011 and $75 \%$ in late 2012, suggesting that there had been no immediate change in practice as a result of the release of the recommendations.

In the United States, adherence to the ASCO recommendation against routine BS, CT or PET for asymptomatic patients with stage $0-$ II breast cancer may be better. Similar to our study, Henry and colleagues included patients with DCIS and stage I and II breast cancer over a time period spanning the release of the ASCO recommendations. ${ }^{26}$ Among 34078 patients who received a diagnosis from 2008 through 2015 in 25 hospital systems included in the Michigan Breast Oncology Quality Initiative, 20.1\% underwent BS, CT or PET within 3 months of diagnosis. The proportion tested significantly decreased over time for patients with DCIS, stage I and stage IIA disease; however, the proportion tested remained stable for patients with stage IIB breast cancer. The reason for each imaging test was abstracted for patients who received a diagnosis in 2014 and 2015 . Notably, in just over half of those tested, the reason was considered valid. Ramsey and colleagues used data from the National Cancer Institute's Surveillance, Epidemiology, and End Results (SEER) Program and linked Premera Blue Cross claims data for patients with cancer diagnosed in western Washington State between 2007 and 2014. ${ }^{27}$ Among 1798 patients with stage 0-II breast cancer, $22 \%$ underwent BS, CT or PET. Rocque and colleagues conducted a retrospective analysis of Medicare claims data for patients with cancer diagnosed in the University of Alabama at Birmingham Health System Cancer Community Network for a time period that largely followed the release of ASCO's Top Five list (2012-2015). ${ }^{28}$ They included 6675 patients with breast cancer and found that only $11.6 \%$ of those with stage 0 II disease underwent BS, CT or PET. For the cohorts in the studies by Ramsey and colleagues and Rocque and 
colleagues, the reason for BS, CT or PET was not obtained and hence the proportions of women undergoing unnecessary staging may have actually been lower.

The apparent greater use of advanced imaging tests for staging among patient with early breast cancer in Canadian relative to US cohorts could be related to both a lack of insurer oversight and a delay in widespread guideline dissemination and/or adoption in Canada. In a survey of a small sample of Canadian breast cancer physicians, although $82 \%$ indicated awareness of at least 1 published breast cancer staging guideline, only $60 \%$ indicated that they had read the ASCO Top Five list and were aware of the specific recommendation against performing routine staging tests for asymptomatic women with stage $0-\mathrm{II}$ breast cancer. ${ }^{29}$ Of note, in our study, patients were more likely to undergo routine BS, CT, PET, MRI or PET if they also had a preoperative chest radiograph. Likewise, in response to the ABIM Choosing Wisely Campaign, on Apr. 4, 2012, the American College of Radiology recommended against preoperative chest radiography for ambulatory patients with unremarkable history and physical..$^{30}$ This recommendation was subsequently endorsed by the American College of Surgeons on Sept. 4, 2013, ${ }^{31}$ and by Choosing Wisely Canada (General Surgery) on Apr. 2, 2014. ${ }^{32}$

Guideline dissemination and adoption is probably also related to the specifics of local practice, as in our study and others there was significant variation in the use of routine staging tests by region (i.e., urban v. rural) and/or type of hospital (i.e., academic v. community). ${ }^{20,26,28}$ Although strategies to improve guideline diffusion and implementation of rules for reimbursement could aid with adherence to staging recommendations, physicians may continue to be swayed by details of the clinical scenario. In our study and others, physicians were more likely to order staging tests according to patient and breast cancer pathologic characteristics potentially associated with a higher risk of recurrence and in patients treated more aggressively (i.e., mastectomy for type of surgery). ${ }^{20,26}$ Although higher $\mathrm{T}$ stage and $\mathrm{N}$ stage are also associated with higher risk of metastases at diagnoses, ${ }^{6,33,34}$ this association has not been confirmed for other factors such as younger patient age, higher tumour grade, HER2-positive disease and triple negative-disease. ${ }^{34}$ However, further research on the risk of metastases at diagnosis by breast cancer subtype is probably warranted, especially for stage IIB disease, where PET has been found to identify metastases in $10.7 \%$ of patients. ${ }^{34}$

Overall, our findings represent the use of BS, CT, nonbreast MRI and PET for routine staging of patients with DCIS and stage I and stage II breast cancer for a single province in a timeframe that spanned the publication of ASCO's Choosing Wisely recommendations. Ascertainment of our cohort was largely unbiased given that we identified eligible patients from the provincial registry. There was minimal risk for misclassification of patients by stage in that only 473 patients $(4.7 \%)$ had neoadjuvant chemotherapy and may have experienced downstaging before surgery. Further, exclusion of these patients in monvariate and multivariate analyses did not affect the results.

\section{Limitations}

To report on advanced imaging tests done unnecessarily for metastastic screening, we examined the indication on the imaging requisition and as per notes in the EMR where necessary. Only 29 tests $(0.5 \%)$ were ordered for unknown reasons. However, we acknowledge that classification of test reason may be associated with some degree of error because the data were reviewed retrospectively. Another limitation is that we could not reliably or completely identify the specialty of the physician ordering BS, CT, MRI or PET. Hence, we could not examine ordering physician specialty in our monovariate and multivariate analyses. Such information may have been useful for knowledge translation. Further, while documentation of unnecessary staging tests implies wasted resources and the prospect for reallocation to areas of need, we have not provided an economic analysis for our setting as others have done in similar studies. ${ }^{16,26-28}$ Finally, we have not yet compared patients who had unnecessary staging tests with those who did not in terms of important outcomes such as use of psychosocial services, time to adjuvant treatment(s) and follow-up imaging tests completed beyond the staging window.

\section{Conclusion}

Almost $30 \%$ of patients with DCIS or stage I or stage II breast cancer diagnosed between 2011 and 2015 in Alberta had at least 1 advanced imaging test completed for routine staging purposes. Despite the release of the ASCO Choosing Wisely recommendations, the utilization of BS, CT and PET did not decrease during the study period. There is an opportunity to improve the quality and value of the care provided to women with early breast cancer, and it is clear that strategies beyond guideline publication are required.

Affiliations: From the Tom Baker Cancer Centre, Calgary, Alta. (Lupichuk); CancerControl Alberta, Alberta Health Services, Calgary, Alta. (Tilley, Surgeoner); and the Cross Cancer Institute, Edmonton, Alta. (King, Joy).

Funding: Funding for this study was awarded by Alberta Health Services' Cancer Strategic Clinical Network.

Competing interests: None declared.

Contributors: S. Lupichuk, D. Tilley, B. Surgeoner and K. King designed the study. S. Lupichuk, D. Tilley and B. Surgeoner acquired the data, which S. Lupichuk, D. Tilley, B. Surgeoner, K. King and A. Joy analyzed. S. Lupichuk and D. Tilley wrote the article, which all authors critically reviewed and approved for publication. 


\section{References}

1. Canadian Cancer Statistics Advisory Committee. Canadian cancer statistics 2018. Toronto (ON): Canadian Cancer Society; 2018. Available: cancer.ca/Canadian-Cancer-Statistics-2018-EN (accessed 2019 Jan. 22).

2. Canadian Partnership Against Cancer. Breast cancer control in Canada: a system performance special focus report. Toronto (ON): Canadian Partnership Against Cancer; 2012.

3. Surveillance \& Reporting. The 2017 report on cancer statistics in Alberta. Edmonton: Alberta Health Services; 2017. Available: public. tableau.com/views/The2017ReportonCancerStatisticsinAlberta/ Highlights? :showVizHome=no (accessed 2019 Jan. 22).

4. Goulart BHL. Value: the next frontier in cancer care. Oncologist 2016;21:651-3.

5. Tran K, Rahal R, Fung S, et al. Choosing wisely in cancer control across Canada - a set of baseline indicators. Curr Oncol 2017; 24:201-6.

6. Myers RE, Johnston M, Pritchard K, et al; Breast Cancer Disease Site Group of the Cancer Care Ontario Practice Guidelines Initiative. Baseline staging tests in primary breast cancer: a practice guideline. CMA7 2001;164:1439-44.

7. Eastern Health. Cancer care clinical practice guidelines. Staging of primary breast cancer. St. John's (NL): Eastern Health; 2011. Available: www. easternhealth.ca/WebInWeb.aspx?d=4\&id=1516\&p=1495 (accessed 2019 Jan. 22).

8. Alberta Health Services. Staging investigations for asymptomatic and newly diagnosed breast cancer. Clinical practice guideline BR-012 version 2. Edmonton: Alberta Health Services; 2012. Available: www. albertahealthservices.ca/assets/info/hp/cancer/if-hp-cancer-guide -br012-staging-investigations.pdf (accessed 2019 Jan. 22).

9. National Comprehensive Cancer Network (NCCN). NCCN Clinical practice guidelines in oncology. Breast cancer version 1. Plymouth Meeting (PA): National Comprehensive Cancer Network; 2014. Available: www.nccn.org/professionals/physician_gls/pdf/breast.pdf (accessed 2019 Jan. 22).

10. Senkus E, Kyriakides S, Penault-Llorca F, et al. Primary breast cancer: ESMO clinical practice guidelines for diagnosis, treatment and follow-up. Ann Oncol 2013;24(Suppl 6):vi7-23.

11. Ravaioli A, Tassinari B, Pasini G, et al. Staging of breast cancer: What standards should be used in research and clinical practice? Ann Oncol 1998;9:1173-7.

12. Puglisi F, Follador A, Minisini AM, et al. Baseline staging tests after a new diagnosis of breast cancer: further evidence of their limited indications. Ann Oncol 2005;16:263-6.

13. Brennan ME. Houssami. Evaluation of the evidence on staging imaging for detection of asymptomatic distant metastases in newly diagnosed breast cancer. Breast 2012;21:112-23.

14. Rayson D, Porter G. Investigations for patients with early-stage breast cancer: oversetting the stage. CMA7 2015;187:860-1.

15. Dinan MA, Curtis LH, Hammill BG, et al. Changes in the use and costs of diagnostic imaging among Medicare beneficiaries with cancer, 1996-2006. 7AMA 2010;303:1625-31.

16. Thavorn K, Wang Z, Fergusson D, et al. Cost implications of unwarranted imaging for distant metastasis in women with earlystage breast cancer in Ontario. Curr Oncol 2016;23(S1):S52-5.

17. Crivello ML, Ruth K, Sigurdson ER, et al. Advanced imaging modalities in early stage breast cancer: preoperative use in the United States Medicare population. Ann Surg Oncol 2013;20:102-10.
18. Markov DV, Soulos PR, Gold HT, et al. Regional-level correlations in inappropriate imaging rates for prostate and breast cancers: potential implications for the Choosing Wisely Campaign. $7 A M A$ Oncol 2015;1:185-94.

19. Linkugel A, Margenthaler J, Dull B, et al. Staging studies have limited utility for newly diagnosed stage I-II breast cancer. 7 Surg Res 2015;196:33-8.

20. Simos D, Catley C, van Walraven C, et al. Imaging for distant metastases in women with early-stage breast cancer: a population based cohort study. CMA7 2015;187:E387-97.

21. Kamal A, Zhang T, Power S, et al. Is advanced imaging in early stage breast cancer ever warranted? Reconciling clinical judgement with common quality measures. 7 Natl Compr Canc Netw 2016;14:993-8.

22. Dull B, Linkugel BA, Margenthaler JA, et al. Overuse of CT chest in patients with stage I and II breast cancer: an opportunity to increase guidelines compliance at an NCCN member institution. 7 Natl Compr Canc Netw 2017;15:783-9.

23. Schnipper LE, Smith TJ, Raghavan D, et al. American Society of Clinical Oncology identifies five key opportunities to improve care and reduce costs: the top five list for oncology. 7 Clin Oncol 2012;30:1715-24.

24. Edge SB, Byrd DR, Compton CC, et al., editors. AfCC cancer staging manual. 7th ed. New York: Springer; 2010.

25. Simos D, Hutton B, Clemons M. Are physicians choosing wisely when imaging for distant metastases in women with operable breast cancer? 7 Oncol Pract 2014;11:62-71.

26. Henry NL, Braun TM, Breslin TM, et al. Variation in the use of advanced imaging at the time of breast cancer diagnosis in a statewide registry. Cancer 2017;123:2975-83.

27. Ramsey SD, Fedorenko C, Chauhan R, et al. Baseline estimates of adherence to American Society of Clinical Oncology/American Board of Internal Medicine Choosing Wisely Initiative among patients with cancer enrolled with a large regional commercial health insurer. 7 Oncol Pract 2015;11:338-44.

28. Rocque GB, Williams CP, Jackson BE, et al. Choosing Wisely: Opportunities for improving value in cancer care delivery? 7 Oncol Pract 2017;13:e11-21.

29. Simos D, Hutton B, Graham ID, et al. Imaging for metastatic disease in patients with newly diagnosed breast cancer: are doctor's perceptions in keeping with the guidelines? F Eval Clin Pract 2015;21:67-73.

30. Choosing Wisely, American College of Radiology. Ten things physicians and patients should question. Philadelphia: American Board of Internal Medicine Foundation; 2012. Available: www.choosingwisely. org/wp-content/uploads/2015/02/ACR-Choosing-Wisely-List.pdf (accessed 2019 Jan. 22).

31. Choosing Wisely, American College of Surgeons. Five things physicians and patients should question. Philadelphia: American Board of Internal Medicine Foundation; 2013. Available: www.choosingwisely. $\mathrm{org} /$ societies/american-college-of-surgeons/ (accessed 2019 Jan. 22).

32. Canadian Association of General Surgeons. General surgery. Six things physicians and patients should question. Choosing Wisely Canada; 2014. Available: https://choosingwiselycanada.org/general-surgery/ (accessed 2019 Jan. 22).

33. Tanaka S, Sato N, Fujioka H, et al. Use of contrast-enhanced computed tomography in clinical staging of asymptomatic breast cancer patients to detect asymptomatic distant metastases. Oncol Lett 2012;3:772-6.

34. Groheux D, Hindie E, Delord M, et al. Prognostic impact of 18FDG-PET-CT findings in clinical stage III and IIB breast cancer. 7 Natl Cancer Inst 2012;104:1879-87. 